\title{
Research on Experiential Learning of Distributed Flip SPOC Model Yanxia Sun ${ }^{1 *}$ and Jinke Wang ${ }^{1}$ \\ ${ }^{1}$ Department of Software Engineering, Harbin University of Science and Technology, Rongcheng, China yier999@163.com
}

Keywords: MOOC; SPOC; Distributed flip; Experiential learning

\begin{abstract}
MOOC (Massive Open Online Course), which is a kind of open-access online course that allows for unlimited participation, while (Small Private Online Course) is not only a MOOC supplement, but also the product of MOOC, which is an integration innovation of traditional teaching method. In this paper, we make a deep research on the experiential learning in SPOC mode. We first start with mastering advanced concepts and the basic process of SPOC theory, and then make a deep analysis of SPOC based on experiential learning theory. Finally we put forwards a whole experiential learning model for distributed flip SPOC. This model is a new attempt and exploration of the learning activity model design in the information environment, which is divided into three parts including learning activities, learning environment and security mechanisms. This scheme is a new attempt and exploration to the design of systematic learning activity model in the information environment.
\end{abstract}

\section{Introduction}

As an extension of online learning, MOOC get numerous people involved in it. MOOC was first proposed in 2008 by Canadian scholar Dave Cormier and Bryan Alexander and first applied by the Canadian scholar George Siemens and Stephen Downes[1]. Since the rise of MOOC, it plays a more and more important role in the field of education, especially higher education. However, in recent years, the climax of university change marked by MOOC in the world has not only led to more extensive and in-depth argument, but also caused the fission from the university cell structure to the higher education decision-making and management mode. In A blog published in EDUCAUSE site called "Into the MOOC Era" triggered a hot debate in academia in 2013. The article mentions the post-MOOC era has emerged on the new changes on teaching methods, platform services, and credit authentication methods. Taking teaching methods as an example, teaching modes and learning modes are being changed from the self-directed online learning to mixed learning, flipping classroom, collaborative learning and research learning. The arrival of the post-MOOC era not only shows that MOOC mode has a strong ability to self-evolutionary adjustment, but also shows that MOOC has advantages and disadvantages.

MOOC's advantages have at least two points. One is massive, "large-scale" makes high-quality resources can be shared through the internet to the whole world, which promote global quality education resources balanced development [2]. Another is open. MOOC is open to learners, but also open to learning content. Like Wikipedia, anyone can participate in the editing of the learning content. At the same time, MOOC's disadvantage is also very prominent, mainly for the following four points. Firstly, the dropout rate is higher. Secondly, the teaching mode is single. Thirdly, the leaning style is fixed. Finally the concept of education is lagging behind.

In reality, the information environment provides a good space and conditions for the inquired learning and collaborative learning. Stressing the study on the online learning will be a constant proposition for improving the effectiveness of the MOOC[3]. In order to make up for the disadvantages and shortcomings of MOOC, many new concepts in the post-MOOC era such as EDUMOOC, MOBIMOOC, SMOOC, DOCC, SPOC are proposed, which are attempts on the online learning[4]. 


\section{The Concept and Case of SPOC}

SPOC is short for "Small Private Online Course". Different with MOOC, SPOC is characterized by "Small, Private". Most scholars think that SPOC is a new model against the disadvantage for the MOOC. Researchers of Harvard University said SPOC is "post-MOOC" [5]. SPOC was proposed by Professor Armando Fox, a famous scholar in the department of Computer Science of Berkeley University. Professor Fox does not agree with the point that SPOC is the competitor of MOOC[6]. He believes that SPOC is not a denial of MOOC, but rather is to better play the role of MOOC. SPOC can use high-quality MOOC resources in schools, classrooms and other similar small groups of the environment [7]. In SPOC, the meaning of "Small" is Minority or Small scale, refers to the number of people learning, generally in dozens to hundreds of people. The meaning of "Private" refers to restriction of learners, only applications who can meet the standards can enter the SPOC course [8]. The basic form of the SPOC is to get MOOC lectures video or online evaluation and other functions in the traditional classroom to assist classroom teaching. Teachers use MOOC to obtain high-quality teaching content and give students rapid feedback through the automatic grading system [9]. Thus SPOC is not a denial of MOOC, but a reasonable complement to MOOC, SPOC's goal is to maximize the degree of MOOC and traditional classroom teaching in-depth integration. As an effective integration with the traditional classroom, SPOC in the classroom teaching has more advantages than the MOOC in some areas and level (see Figure 1). Because SPOC better achieves the effective integration of MOOC and traditional classroom, the characteristic of SPOC is to make up the deficiency of MOOC in the aspects of high dropout rate, single teaching mode, and the backwardness of teaching concept.

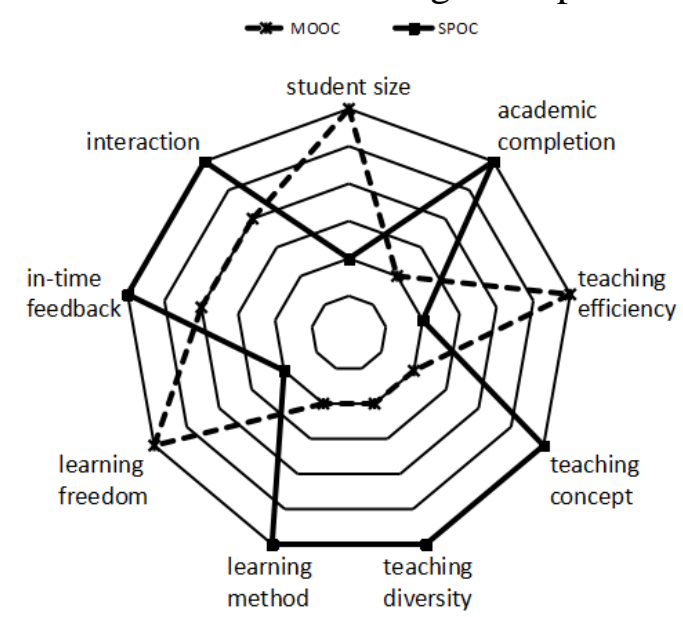

Figure 1. Compared result of SPOC and MOOC

Thus, SPOC can produce better learning outcomes. Compared with the MOOC, SPOC is able to customize courses and provide more targeted and great professional support by defining access conditions and the scale of the course, so it can more effectively solve the problem than MOOC [10]. Therefore, as Professor Fox said, SPOC and MOOC is definitely not opposed to each other, SPOC and MOOC organic integration together is the only way to learn online, but also a new force in traditional classroom learning.

\section{Design of Experiential Learning Model}

Design Overview. Making SPOC as an effective complement to MOOC and deeply integrating with classroom teaching, is an innovation of the learning platform, learning resources and learning environment. In addition to learning mode, the internal drive to learning and external security system to support the teaching activities is also included. Based on the study of the relevant teaching model, the author puts forward the design of systematic learning activities under the information environment (see Figure 2). This design embodies the characteristics of the SPOC learning activity model, the experiential learning environment, and the external service system as 
the guarantee mechanism.

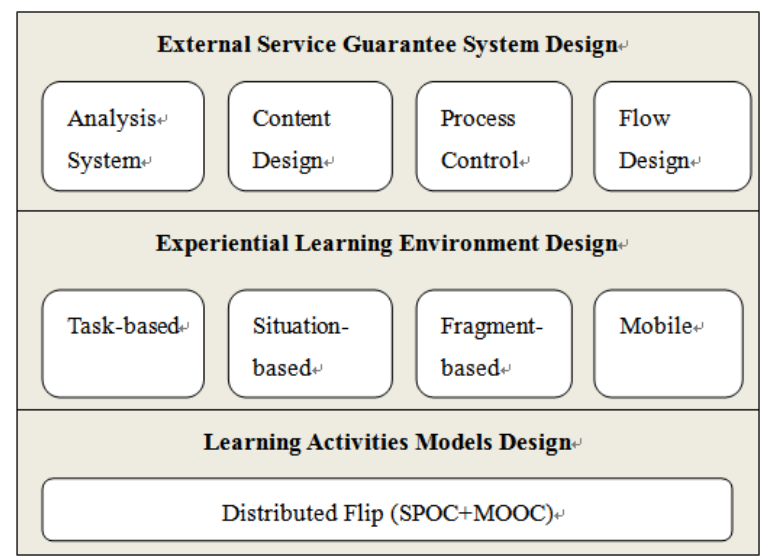

Figure 2. Experiential Learning Model

The design is divided into three parts that are learning activities, learning environment and security mechanisms. The learning activities are based on the learning drive and the flip mode and combine the advantages of SPOC and MOOC organically. The flip mode is an attempt at reforming MOOC teaching at Stanford University. The aim of it is to form the collaborative style of flip class with the establishment of a MOOC curriculum. The learning environment provides experiential learning environment based on ubiquitous learning theory in four aspects: fragment-based, mobile, task-based and situation-based. From the view of performance-based teaching design, the safeguard mechanism provides the external service guarantee from the four perspectives of "learning analysis and design", "learning content development", "learning process control" and "learning process information" system.

Experiential Learning Activities. The distributed flip SPOC model is the formation of the cooperative organization of the flip classroom by means of MOOC courses. In this model the activities under the class have the overall MOOC model of resource construction and development, testing, practice, feedback evaluation, interactive discussion and so on; the class adopts the restrictive, small-scale, SPOC teaching model.

Experiential learning activities design draws on the distributed flip, to build a learning activity model based on SPOC (see Figure 3 3). The module rounds the structure from the perspective of teachers and learners and reflects the cycle of the logical correlation between learning activities. Learning activities are divided into four parts: learner-centered, task-based collaborative team, learner-centered, task-based autonomous learning and collaborative learning, teacher-led, task-based rehabilitation and learning, Teacher-led, task-based internalization of knowledge and skills.

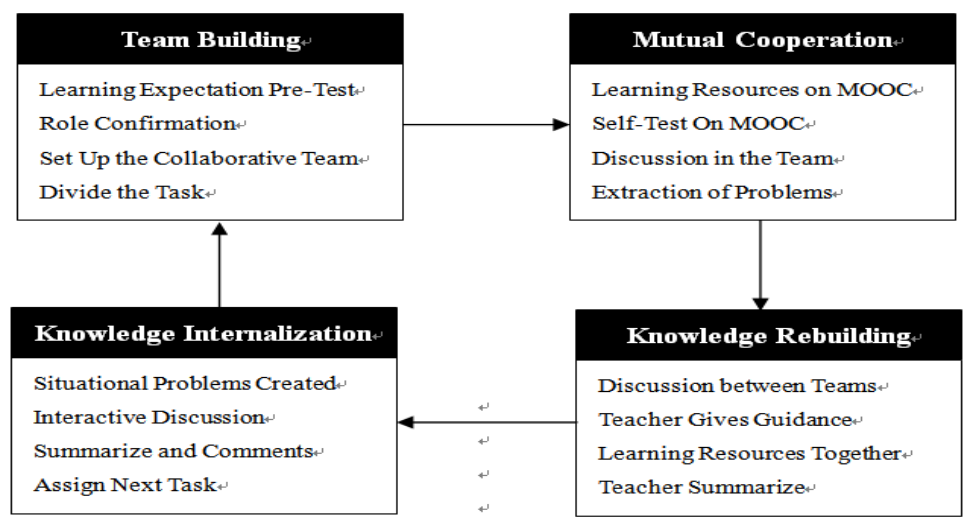

Figure 3. SPOC Learning Activity Loop

Experiential Ubiquitous Learning Environment. The study of experiential ubiquitous learning environment design pattern and teaching organization form is mostly based on the condition of 
students' autonomous learning, and there is a problem of insufficient interaction between teachers and students, between students and students. From the theory of education, the most effective teaching method is still face to face teaching between teachers and students [11]. The interaction between teachers and students contains a lot of teaching information in the voice of intonation, gestures, which is precisely the performance of experiential learning. While in the information age, asynchronous learning is inevitable, using network communication technology allows learning activities to break through time and space bottlenecks and achieves anytime, anywhere ubiquitous learning. How to combine the "experience" in the class with the "ubiquitous" online is the key factor in constructing experiential ubiquitous learning environment. An experiential ubiquitous learning environment (see Fig. 4) was built based on situational task-driven, with two lines (class and online) as learning activities.

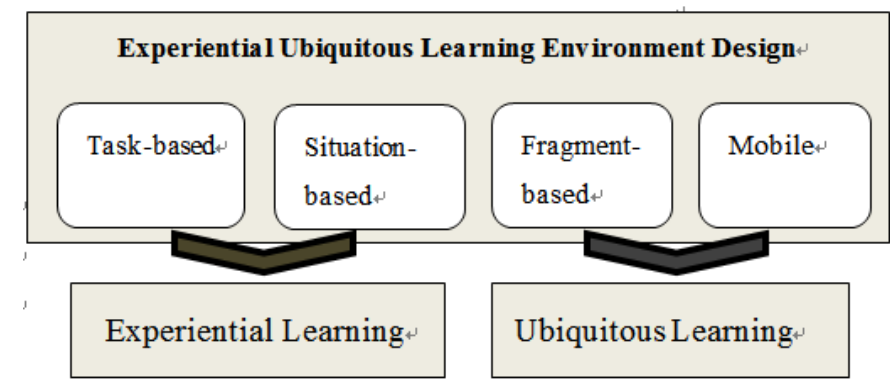

Figure 4. Experiential Ubiquitous Learning Environment

The first part in the environment is experiential learning. Task-based and situational learning is an important means of experiential learning. Task-driven not only emphasizes the acquisition of results, pay more attention to feelings, perception, experience and other process experience to obtain. At the same time, the task-based learning environment provides real environment support for interaction between teachers and students. In the learning activities, the task is through the learning process. Learning expectation before the test, the establishment of collaborative team, the autonomy and collaborative learning, knowledge below the class and skills study and internalization in class are carried out around the task. In the classroom, teachers create a task-based context and present the topic of discussion. The creation of the situation is a collection of realistic scenes and online virtual worlds. The key point of task-based and contextualization of learning activities lays in the fact that task and situation as well as meet teaching requirements of knowledge, must also meet practical needs.

The second part is called ubiquitous learning. Seen from the theoretical concept, so-called ubiquitous learning just about anyone, at any time, any place, on any computing device to obtain any required learning resources. In the current information environment, the characteristics of ubiquitous learning are characterized by fragmentation and mobility. In the process of ubiquitous learning, how learners take advantage of the fragmented and mobile learning environment to make it effective in learning is affected by many factors: the ubiquitous learning resources, the ubiquitous learning model and the ubiquitous learning environment.

Service Guarantee System. The process of teaching design is to clarify the problem, determine the cause of the problem and impose interventions [12]. It is more concerned about the feasibility of solving the problem, that is, to solve the problem of "available resources" and "constraints." which can be understood as the "input" and "output" in economics. Practical significance is embodied in finding a compromise and balance between a serial of constraints and a range of possible teaching measures, in pursuit of the maximization of teaching effectiveness and efficiency. At this time, the teaching design is no longer a linear and procedural system implementation process, but a process of seeking the "constraint" and determining the "available measures". "Constraints" is achieved by the learning characteristics of analysis and learning needs analysis. "Available measures" is the design of the learning resources, learning process and learning environment. Teaching design choose effective "available measures" according to "constraints" to achieve optimal teaching effectiveness (see Figure). 


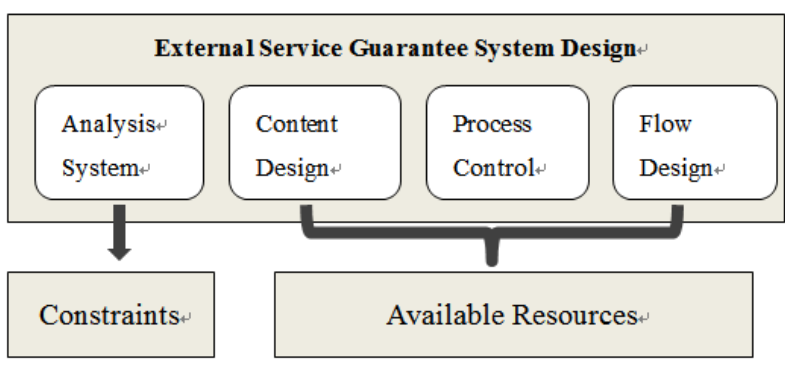

Figure 5. External Service Guarantee System

Various behaviors in the learning process will be recorded and the information will form data collection that will serve as a data source for data analysis. Learning analysis based on these data can get the learning details of learners and can provide the basis for personalized learning guide. Taking micro-course video watching as an example, we can get data of watching time, watching times and "fast-forward" point through the information platform.

Through processing these data, we can learn what micro-video is learner interest, what point in micro-video is the learner's attention. The result of the analysis can provide reference for the making of the micro - curriculum video, can judge the learning behavior of the learners, provide the basis for organizing the activities and arrange the tasks.

\section{Conclusions}

No matter how MOOC is regarded, for some time in future, MOOC will still be a research focus in the area of education. The so-called "post-MOOC era" is only the transformation of MOOC. The transformation of MOOC involves all aspects which explore new ideas for online learning in the information environment. Compared with EDOMOOC, MOBIMOOC, SMOOC, DOCC and other MOOC variants, SPOC make up the natural disadvantages and shortcomings of MOOC in the traditional classroom teaching. At the same time, we should clearly see that the research of learning mode, in which the key points includes learning platform construction, learning resource construction and learning environment construction, lacks effective learning experience, lacks effective supervision of learners, lacks effective control of learning process, lacks a comprehensive service security system. Thus the learning effect is difficult to guarantee. In this paper, we propose a whole learning activities with distributed flip SPOC learning activity as the core, with the external service system as the guarantee mechanism and the experiential ubiquitous learning environment to stress the learning motivation, which is a new attempt and exploration.

\section{Acknowledgements}

This work was supported by Education and Teaching Research Project of Harbin University of Science and Technology (No. 420160020), Philosophy and Social Sciences Research Program of Heilongiiang Province (No.16WWC02), and Educational and Scientific Research of Higher Education Institute of Heilongjiang Province (No.16Q080).

\section{References}

[1] D. Mioduser, R. Nachmias: New Literacy for the Knowledge Society [J]. International Handbook of Information Technology in Primary and Secondary Education, 2008, (5): 23-42.

[2] Trang Phan, Sara G. McNeil and Bernard R. Robin: Students' Patterns of Engagement and Course Performance in a Massive Open Online Course [J]. Computers \& Education, 2015: 30-36.

[3] Gary W Matkin: Open Educational Resources in the Post MOOC Era [J]. eLearn, 2013, Vol.2013 (4): 36-43

[4] Aguaded-Gomez, J Ignacio: The MOOC Revolution: A New Form of Education from the 
Technological Paradigm. COMUNICAR. 2013: 29-36

[5] P. Adamopoulos: What makes a great MOOC? An Interdisciplinary Analysis of Student Retention in Online Courses [J]. In Thirty Fourth International Conference on Information Systems, Milan, 2013: 31-38.

[6] Ye-qin Kang: The New Age of Online Education-SPOC [J]. Institute of Education Tsinghua University, 2014, (35): 85-93.

[7] Fox, A. Patterson: Software Engineering Curriculum Technology Transfer: Lessons Learned from MOOCs and SPOCs [R]. UC Berkeley Technical Report. 2014: 18-26.

[8] Wei Xu, Yong-zheng Jia, Armando Fox, David Patterson: From MOOC to SPOC - Academic Conversation Based on MOOC Practice in University of California Berkeley and Tsinghua University [J]. Modern Distance Education Research, 2014, (4): 13-22.

[9] Jun-chao Zhang: Push Forward With the Education Reform From "Teach" to "Learn" [J]. Journal of Higher Education, 2012, (08): 104-109.

[10]M. Madi, M. Griffiths, A. Rushton: Creating a learning culture for developing clinical reasoning through postgraduate manipulative physiotherapy education [J]. Manual Therapy, 2016, 25-32.

[11] Abdullah Konak, Tricia K. Clark, Mahdi Nasereddin: Using Kolb's Experiential Learning Cycle to improve student learning in virtual computer laboratories [J].Computers \& Education, 2014, Vol.72 31-39

[12]D. A. Kolb: Experiential Learning: Experience as the Source of Learning and Development [M]. New Jersey: Prentice-Hall, 2014: 41-50 